\title{
G-Quadruplex Identification in the Genome of Protozoan Parasites Points to Naphthalene Diimide Ligands as New Antiparasitic Agents
}

Efres Belmonte-Reche, ${ }^{\dagger}$ Marta Martínez-García, ${ }^{\dagger}$ Aurore Guédin, ${ }^{\ddagger}$ Michela Zuffo, ${ }^{\S}$ Matilde Arévalo-Ruiz, ${ }^{\dagger}$ Filippo Doria, ${ }^{\S}$ Jenny Campos-Salinas, ${ }^{\dagger}$ Marjorie Maynadier, $"$ José Juan López-Rubio, ${ }^{\perp}$

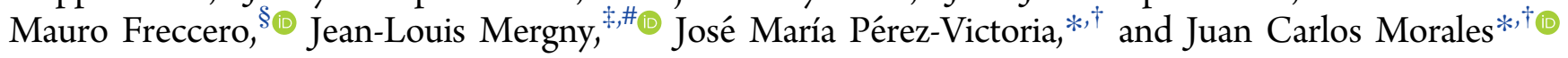

${ }^{\dagger}$ Department of Biochemistry and Molecular Pharmacology, Instituto de Parasitología y Biomedicina, CSIC, PTS Granada, Avda. del Conocimiento, 17, 18016 Armilla, Granada, Spain

${ }^{\ddagger}$ ARNA Laboratory, Université de Bordeaux, Inserm U1212, CNRS UMR5320, Institut Européen de Chimie Biologie (IECB), 2 Rue Robert Escarpit, 33607 Pessac, France

${ }^{\S}$ Department of Chemistry, University of Pavia, Via Taramelli 10, 27100 Pavia, Italy

"Dynamique des Interactions Membranaires Normales et Pathologiques, CNRS UMR 5235, Université de Montpellier, 34095

Montpellier, France

${ }^{\perp}$ CNRS, 5290, IRD 224, University of Montpellier (UMR “MiVEGEC”), INSERM, 34394 Montpellier, France

${ }^{\#}$ Institute of Biophysics, AS CR, v.v.i. Kralovopolska 135, 61265 Brno, Czech Republic

Supporting Information

ABSTRACT: G-quadruplexes (G4) are DNA secondary structures that take part in the regulation of gene expression. Putative G4 forming sequences (PQS) have been reported in mammals, yeast, bacteria, and viruses. Here, we present PQS searches on the genomes of T. brucei, L. major, and $P$. falciparum. We found telomeric sequences and new $P Q S$ motifs. Biophysical experiments showed that EBR1, a 29 nucleotide long highly repeated PQS in T. brucei, forms a stable G4 structure. G4 ligands based on carbohydrate conjugated naphthalene diimides (carb-NDIs) that bind G4's including hTel could bind EBR1 with selectivity versus dsDNA. These ligands showed important antiparasitic activity.

$\mathrm{IC}_{50}$ values were in the nanomolar range against $T$. brucei with high selectivity against MRC-5 human cells. Confocal microscopy confirmed these ligands localize in the nucleus and kinetoplast of T. brucei suggesting they can reach their potential G4 targets. Cytotoxicity and zebrafish toxicity studies revealed sugar conjugation reduces intrinsic toxicity of NDIs.

\section{INTRODUCTION}

G-quadruplexes (G4) are secondary structures formed by guanine-rich DNA and RNA sequences. Their basic motif is a four-guanine tetrad linked through Hoogsteen hydrogen bonding that stacks on top of other G-tetrads helped by interactions with cations, such as $\mathrm{Na}^{+}$or $\mathrm{K}^{+}$. G4 topologies are quite diverse and depend on base sequence, loop connectivity, and the syn or anti guanine configuration along the oligonucleotide folding. ${ }^{1}$

G4 sequences are overrepresented in certain key regions of the genome ${ }^{2}$ such as promoters, enhancers, insulators, origins of replications, and telomeres. These findings suggest that G4 have important functions in cellular and genetic processes. Visualization and genome mapping experiments ${ }^{3}$ suggest that G-quadruplex DNA can be formed when DNA single strands are exposed during replication or transcription. G4 structures pose challenges to replication, and G4 helicases are essential to unwind them and thus maintain genetic stability. ${ }^{4}$ Sarkies et al. also suggested that G4 DNA are involved in the maintenance of epigenetic regulation of gene expression. ${ }^{5}$

Putative G-quadruplex sequences ( $P Q S$ ) have been found in organisms other than humans, such as other mammals, ${ }^{6}$ yeast, ${ }^{7}$ bacteria, ${ }^{8}$ and viruses. ${ }^{9}$ In contrast, few data have been reported of G4 in parasites. ${ }^{10}$ The malaria-causing parasite Plasmodium falciparum has an extremely AT rich DNA (>80\%), which in principle lowers the possibilities of G4 formation. ${ }^{11}$ Nevertheless, successive bioinformatic searches have identified several putative quadruplex sequences $^{1 \mathrm{e}, 12}$ that may play a role in antigenic variation and diversification. ${ }^{10,12 a}$ Bottius et al. ${ }^{13}$ reported the existence of a common degenerate motif GGGTTYA (where $\mathrm{Y}$ is $\mathrm{T}$ or $\mathrm{C}$, PfTel) in the DNA of $P$. falciparum and localized it mainly in the $1.3 \mathrm{~kb}$ (average) telomeric regions of the parasite chromosomes. This

Received: November 15, 2017

Published: January 11, 2018 


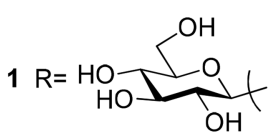

$\beta-g l c$
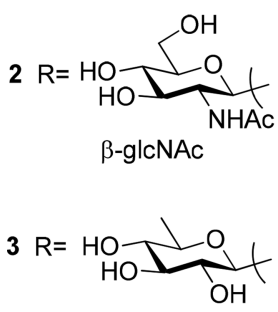

$\beta$-6-deoxyglc
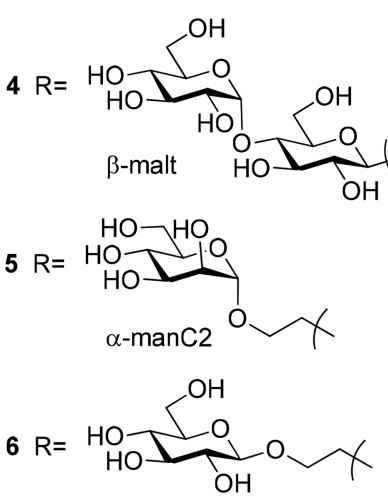

$\beta-g l c C 2$
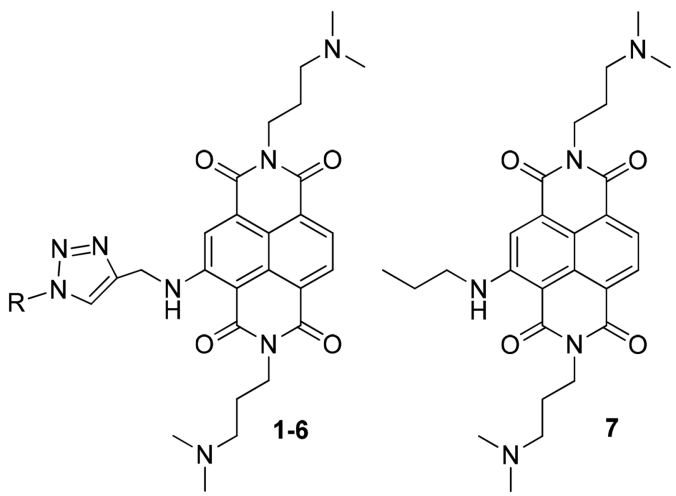

Figure 1. Carb-NDI family of G-quadruplex ligands studied in this work.

degenerate motif has also been found in other Plasmodium species. ${ }^{14}$ Interestingly, its repetitive sequence being different from the human telomeric one (GGGTTA; hTel) in principle gives the opportunity of a selective targeting. These repeats and other G4 forming sequences are abundant in var gene regulatory regions. ${ }^{10,12,15}$ The var genes, which regularly recombine to generate new variants, ${ }^{16}$ code for PfEMP1, a family of variant surface antigens responsible for preventing the infected erythrocytes from being recognized by the host's immune system by continuously presenting different PfEMP1 proteins. ${ }^{17}$ This phenomenon of antigenic variation is produced because the parasite expresses an exclusive PfEMP1 protein but frequently switches to express different var genes. ${ }^{17}$ The presence of G4 sequences in var gene regulatory regions has been suggested to influence var gene recombination and/or switching. ${ }^{12 a}$

Potential G4 sequences have been scarcely investigated in parasites of the Trypanosomatide order. Trypanosoma brucei and Leishmania major are responsible for two life-threatening neglected diseases, sleeping sickness (or African trypanosomiasis) and leishmaniasis, respectively. Both species present telomeric regions with tandem repetitions of the hTel sequence, ${ }^{18}$ and their variability has been related to gene expression critical for their survival, chromosomic polymorphisms, and rearrangements. ${ }^{19}$ In these telomeric regions G-rich sequences facilitate the switching of the important variable surface glycoprotein (VSG) genes, ${ }^{10,20}$ which are responsible for the antigenic variation that this parasite uses to evade the immune system. ${ }^{21}$ However, the direct involvement of quadruplexes in this process has yet to be established. On the other hand, $T$. brucei presents a single mitochondrion of which the genome, also known as kinetoplastid DNA, contains several open reading frames $(\mathrm{ORF})$ that require editing to become translatable mRNAs. ${ }^{22}$ Nine of these ORFs are pan-edited, leading to the site-specific insertion and deletion of hundreds of U-nucleotides. ${ }^{23}$ Recently, 27 PQS were detected in eight of the nine pan-edited mitochondrial pre-mRNA transcripts of $T$. brucei. ${ }^{23}$ Interestingly, the stepwise editing of these pre-mRNAs progressively resolves these G4 structures generating less structured ORFs, suggesting that they could be due to an evolutionary driving force for RNA editing in trypanosomes. ${ }^{23}$

Drugs currently used to treat neglected diseases have limited efficacy, are hampered by appearance of resistance and/or are toxic. There is therefore an urgent need to find new targets for the development of drugs, ${ }^{24}$ and G4 could be an attractive alternative target. In fact, due to their roles in a number of biological processes, G4 have been proposed as potential therapeutic targets in cancer ${ }^{25}$ and small molecule G4 ligands have been reported for the past 2 decades as antitumor drugs. ${ }^{4 \mathrm{~d}, 26} \mathrm{G} 4$ have also been suggested as targets for treating virus such as HIV, and several G4 ligands have been reported as potential drugs. ${ }^{27}$ In the case of parasites, De Cian et al. ${ }^{28}$ reported that several classical G4 ligands such as BRACO-19, TMPyP4, PIPER, telomestatin, and others were capable of binding the degenerative motif of $P$. falciparum telomere GGGTTYA. Actually, the Phen-DC family exhibited the most noticeable stabilization effect over all three PfTel tested, yet failed (as all the other compounds used) to discriminate against the hTel sequence. Similarly, the bis-quinacridine BOQ1 ligand showed binding to the UpsB-Q G-quadruplex, a G4 formed in an upstream regions of groupB var genes of $P$. falciparum. ${ }^{12 \mathrm{~b}}$ Recently, a bis-pyrrolo[1,2-a]quinoxaline family of compounds has been described to bind two PfTel G4 sequences and to display antimalarial activity, ${ }^{29}$ and TMPyP4 and telomestatin were reported to inhibit $50 \%$ growth of P. falciparum at 5 and $35 \mu \mathrm{M}$ concentration, respectively. ${ }^{30}$ To the best of our knowledge, these are the only reported examples of G4 ligands with antiparasitic activity.

In a previous work we synthesized and evaluated a new family of carbohydrate naphthalene diimide derivatives (carbNDI) as G4-binders and antitumor drugs (Figure 1). ${ }^{31}$ The binding results to G4 targets and nuclear localization in cells suggested that this family of ligands interacts with G4 structures.

The initial purpose of using sugar-conjugated anticancer drugs was to take advantage of the Warburg effect and the overexpression of GLUT transporters in cancer cells due to the high energy requirements. ${ }^{32}$ We envisioned that sugar conjugation in antiparasitic drugs could be useful for a better uptake of the drug in the parasite. In fact, glucose transporters play a central role in their survival. The LGT family of transporters of Leishmania spp. ${ }^{33}$ relate to the human GLUT1 in sequence and structure and have higher glucose affinity than the human counterpart. ${ }^{34}$ Additionally, they have been found to be critical for parasite survival since LGT null mutants are more susceptible to oxidative stress and have reduced viability at high temperatures or under nutrient deficiency. ${ }^{35}$ In Plasmodium falciparum, the PfHT1 protein has significant sequence identity to the human GLUT1 ${ }^{36}$ and broad specificity for hexoses. The main sugar transporter identified in the bloodstream form of Trypanosoma brucei is THT1 which is a low-affinity and high- 
Table 1. Most Frequent PQS Found in L. major, T. brucei, and P. falciparum Genomes and Number of Occurrences ${ }^{a}$

\begin{tabular}{|c|c|c|c|}
\hline & PQS & name & frequency \\
\hline \multirow[t]{8}{*}{ L. major } & GGGTTAGGGTTAGGGTTAGGG & hTel & 465 \\
\hline & GGGAGGGAGGGAGGG & & 26 \\
\hline & GGGTGAGCGGGTGGGGGTCAGTGGG & & 22 \\
\hline & GGGGTGGGCCACGCGGGGACAGGACGGG & & 21 \\
\hline & GGGCGTGGGTGTGGGTGTGGG & & 19 \\
\hline & GGGCGAGGGGGAGGGGGGTGCTGGG & & 17 \\
\hline & GGGAAAAGAAGGGGAAGGGGTAGGG & & 16 \\
\hline & GGGTGGGTGGGTGGG & T30693 & 16 \\
\hline \multirow[t]{3}{*}{ T. brucei } & GGGCAGGGGGTGATGGGGAGGAGCCAGGG & EBR1 & 33 \\
\hline & GGGTTAGGGTTAGGGTTAGGG & hTel & 26 \\
\hline & GGGAGAGGGAGAGGGAGAGGG & & 5 \\
\hline \multirow[t]{7}{*}{ P. falciparum } & GGGTTTAGGGTTCAGGGTTTAGGG & PfTel & 84 \\
\hline & GGGTTTAGGGTTTAGGGTTTAGGG & PfTel & 67 \\
\hline & GGGTTCAGGGTTTAGGGTTCAGGG & PfTel & 63 \\
\hline & GGGTTTAGGGTTTAGGGTTCAGGG & PfTel & 63 \\
\hline & GGGTTCAGGGTTTAGGGTTTAGGG & PfTel & 58 \\
\hline & GGGTTTAGGGTTCAGGGTTCAGGG & PfTel & 26 \\
\hline & GGGTTCAGGGTTCAGGGTTTAGGG & PfTel & 19 \\
\hline
\end{tabular}

capacity facilitative protein that takes advantage of the high concentration of glucose in the blood. ${ }^{37}$

In this work, we have made a genomic search of PQS for $T$. brucei, L. major, and P. falciparum. We have localized G4 sequences in their genomes and evaluated their possible importance for the parasite survival. We have evaluated a unique G4 sequence found in T. brucei (EBR1) for its ability to form stable G-quadruplex using biophysical methods. Furthermore, the carbohydrate-NDIs have been investigated as potential ligands of EBR1 and evaluated as antitrypanosomal, antileishmanial, and antimalarial agents together with their toxicity in human cells and in zebrafish embryo. Finally, location of carb-NDIs inside T. brucei was also studied.

\section{RESULTS AND DISCUSSION}

Putative G-Quadruplex Sequences (PQS) Search in $T$. brucei, $P$. falciparum, and $L$. major Genomes. The possibility of G-quadruplex formation was analyzed using the online algorithm software for PQS-search engine called QGRS Mapper since it is a user-friendly, commonly used algorithm. ${ }^{38}$ The genomes were downloaded from tritrypDB (http:// tritrypdb.org for T. brucei, version 5.1, accessed January 2016), the Sanger Institute (http://www.sanger.ac.uk for $L$. major, version 6.1, accessed June 2016), and plasmoDB (http://plasmodb.org for P. falciparum, version 3.0, accessed January 2016), and only the positive strands were included. The results were set to leave out overlapping PQS. Additional parameters were set to default ( $\max$ length $=30$, min G-group size $=3$, loop size $=3-10$ ). With these parameters, $466 \mathrm{PQS}$ were found for $P$. falciparum, whereas Smargiasso et al. ${ }^{12 \mathrm{~b}}$ reported $891 \mathrm{PQS}$ when searching through the whole genome. The resulting variation is probably due to the differences in the parameter criteria (Smargiasso used a loop range of 0-11) and in the genome version. A similar number of PQS (433) was also detected in T. brucei, although its genome is larger than the one of $P$. falciparum ( $32 \mathrm{vs} 23 \mathrm{Mbp}$ ) and its composition is more GC-rich (45\% T. brucei, 20\% P. falciparum). L. major displayed 4719 PQS, 10 times more than T. brucei, despite having similar genomic size and a composition of 57\% GC. Both of these genomic parameters cannot explain the big difference in PQS detection rates. These tendencies were better observed when comparing parasite PQS densities (number of PQS/10.000 bases) $0.15,0.24$, and 1.42 for T. brucei, $P$. falciparum, and L. major, respectively. Large differences were also observed between chromosomes. L. major's chromosomes $4,13,17,34$, and 36 displayed very high PQS concentration, while chromosomes 12 and 14 of P. falciparum have a very low density of G4-prone sequences (Table S2 in Supporting Information). T. brucei displayed low PQS concentration in its entire genome.

The relevance of the PQS found can be estimated based on the G-score, a validation system on QGRS-mapper. The algorithm tends to emphasize shorter loops with equal size and higher number of guanine tetrads. However, false positives (where high G-score PQS are unable to form G4) and false negatives (where low G-score PQS are able to form stable G4) are given sometimes as results. To solve these potential errors, several other algorithms have been developed, such as G4hunter. ${ }^{1 \text { e }}$ G4-hunter validates PQS ability to form G4 by taking into account G-richness ( $\mathrm{G}$ in sequence) and skewness (G/C asymmetry with the complementary strand) of the PQS area and thus drastically reduces false results. We decided to validate PQS results simply by frequency. Higher frequencies are in principle less prone to be random nucleotide sequences without a biological role. At the same time, all highly frequent PQS found for the examined parasites are verified G4-forming sequences. For L. major and T. brucei these PQS include the hTel sequence, and for P. falciparum the variety of PfTel sequences (Table 1). In T. brucei we also found a highly frequent new nontelomeric sequence that however was given a poor G-score by the search engine. This sequence (EBR1) was found 33 times (Table 1).

When we checked the location of EBR1 in T. brucei genome, we found it was repeated 22 times between percentile 34.2 and 35.2 of chromosome 9, where it was located inside several genes coding, among others, for a purine nucleoside transporter (NT10), a calpain-like cysteine peptidase, an adenylosuccinate lyase, and other proteins with unknown function. The rest of the EBR1 sequences were found between percentile 6.6 and 6.9 of chromosome 11 and inside a gene coding for an iron/ 
a

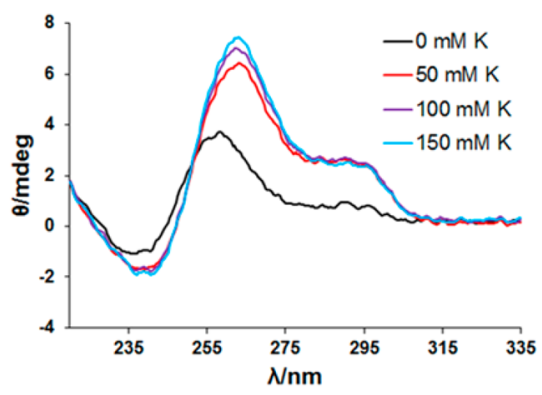

C

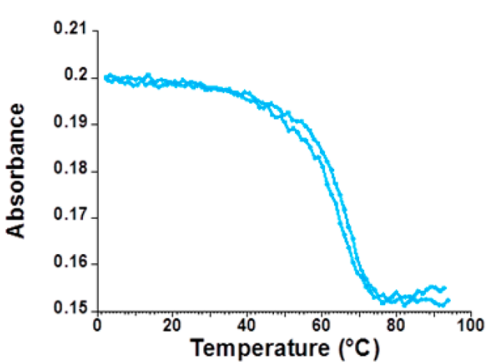

b

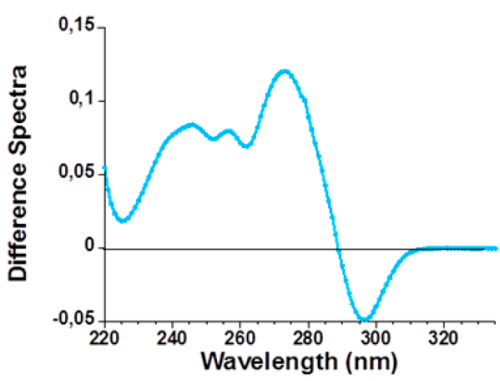

d

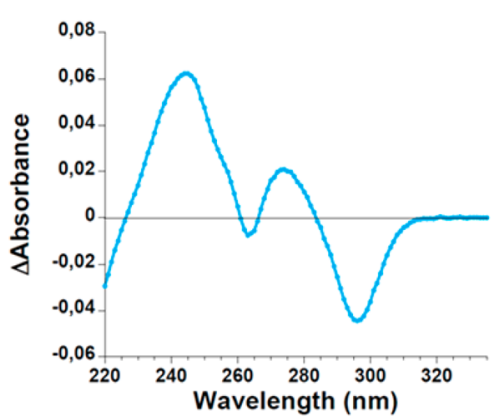

Figure 2. Characterization of EBR1 sequence: (a) CD spectra in the absence and presence of different concentrations of $\mathrm{K}^{+}$; (b) thermal difference spectra (TDS); (c) UV-monitored thermal denaturation experiment at $295 \mathrm{~nm}$; (d) isothermal difference spectra at $25^{\circ} \mathrm{C}$ (IDS).

ascorbate oxidoreductase. The hTel sequences in L. major and T. brucei were mainly localized in the telomeric regions as expected. For T. brucei, some of these sequences were found to be in or in between VSG genes, yet also throughout nontelomeric areas affecting a trans-sialidase neuraminidase and several unknown proteins. PfTel sequences found in $P$. falciparum were mostly localized in the telomeric areas (percentile >99.9) and affecting PfEMP1 expressing genes as it was reported earlier.

G4 Formation by T. brucei EBR1 Sequence. Due to the novelty and frequency number in T. brucei genome, the EBR1 sequence (Table 1) was selected and analyzed for its ability to form G-quadruplex. Circular dichroism (CD) spectroscopy was first carried out in the absence and presence of increasing concentrations of $\mathrm{K}^{+}$to investigate G-quadruplex formation. ${ }^{39}$ EBR1 CD spectra showed positive signals at 260 and $295 \mathrm{~nm}$ and a negative signal at $240 \mathrm{~nm}$, suggesting a predominantly parallel G-quadruplex conformation (Figure 2a). When CD was recorded in sodium buffer conditions, the spectra were similar but with lower intensity (Figure S1). It is important to mention that G4 seems to be partially folded even in the absence of cations (Figure S1) and CD signals increase with accumulative amount of cations. Other examples have been reported of G4 formation in the absence or low concentration of monovalent cations. $^{40} \mathrm{~A}$ mutated EBR1 sequence (EBR1-mut) where several guanine residues were changed to adenine or thymine was also examined for comparison (Figure S2). In this case, no $\mathrm{CD}$ signals characteristic of G-quadruplex formation were detected and only small changes were observed after $\mathrm{K}^{+}$or $\mathrm{Na}^{+}$ addition.

UV thermal difference spectroscopy (TDS) ${ }^{41}$ was recorded on EBR1 (Figure 2b) by subtracting spectra at 93.5 and $2.7^{\circ} \mathrm{C}$. Major positive peaks at 247, 257, and $274 \mathrm{~nm}$, together with a negative peak at $296 \mathrm{~nm}$, are a typical signature of Gquadruplex folding. UV melting ${ }^{42}$ of EBR1 monitored at 295 $\mathrm{nm}$ showed the usual negative sigmoidal curve for Gquadruplex with a $T_{\mathrm{m}}$ value of $65{ }^{\circ} \mathrm{C}$ (Figure 2c). The reverse cooling experiment showed an almost overlapping curve (Figure 2c). IDS spectra on EBR1 were obtained by taking the difference between the absorbance spectra of folded and unfolded oligonucleotides. These spectra were respectively recorded before and after potassium cation addition $(100 \mathrm{mM}$ $\mathrm{KCl}$ ) at $25{ }^{\circ} \mathrm{C}$ (Figure $2 \mathrm{~d}$ ). This signature is characteristic of a G4 structure, as in the case of the TDS spectra. The spectra showed major positive peaks at 244 and $274 \mathrm{~nm}$ with a negative peak at $296 \mathrm{~nm}$.

Proton NMR experiments were run on the unlabeled EBR1 sequence at 25 and $60{ }^{\circ} \mathrm{C}$, close to the $T_{\mathrm{m}}$ measured by UV melting. Both spectra displayed the characteristic imino peaks in the 10-12 ppm range and none at higher field (Figure S3), suggesting the exclusive folding into G4 structures. ${ }^{43}$ However, the spectra displayed a complex mixture of signals, indicating the coexistence of more than one conformation. Even close to the melting temperature a favored one could not be identified, suggesting that they all have similar stability.

After validation of EBR1 folding into a G4 structure, we proceeded to test ligand binding. FAM and TAMRA fluorophores were attached to the $5^{\prime}$ - and $3^{\prime}$-ends of EBR1 sequence (EBR1-FT; see Table S1) to run FRET experiments. Preliminary UV melting and CD experiments were carried out on EBR1-FT. The results demonstrated that the stability and folding topology are in good agreement with those obtained for the unlabeled EBR1 sequence (Figure S4).

Next, two of our G-quadruplex ligands, the carb-NDI 6 and the reference aglycone-NDI (7), were tested for binding to the EBR1 G4 structure using FRET. Carb-NDIs 1-6 and aglycone NDI 7 have previously shown binding to several G-quadruplex structures (hTel, c-myc, human minisatellite, and Bombyx telomere) with certain selectivity for quadruplexes over DNA duplexes. $^{31}$ FRET-based melting assays were performed in the presence of 10 and $50 \mathrm{mM}$ concentrations of $\mathrm{K}^{+}$, with $0.5,1$, and $2 \mu \mathrm{M}$ of compound 6 or 7 and $0.2 \mu \mathrm{M}$ of the oligonucleotide. Both compounds showed binding to EBR1, and $\Delta T_{\mathrm{m}}$ values were higher for aglycone-NDI 7 than for 

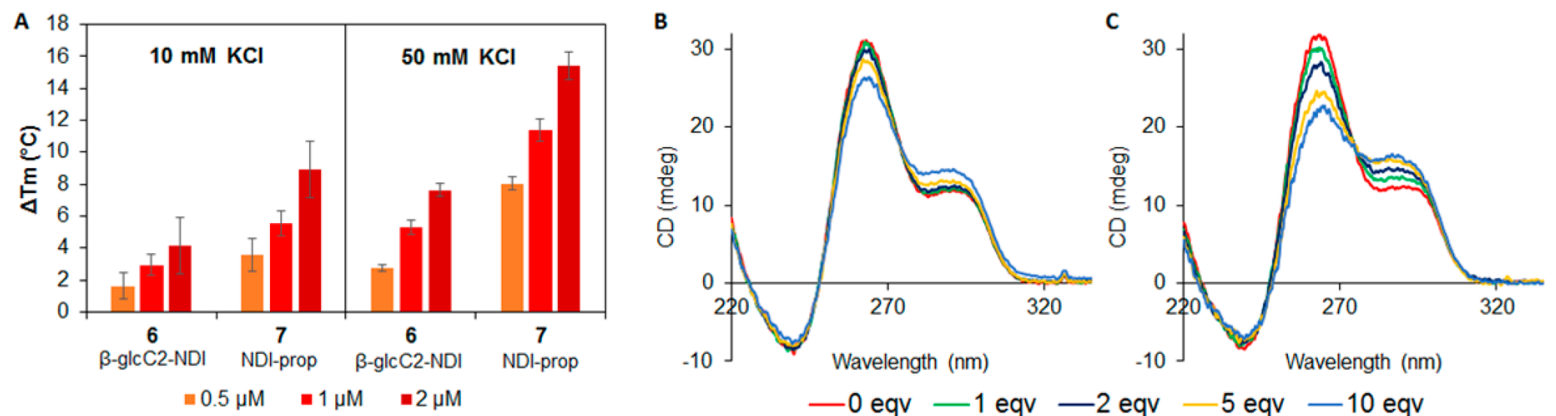

Figure 3. (A) FRET melting assay. Thermal stabilization induced by the tested compounds 6 and $7(0.5,1$, and $2 \mu \mathrm{M})$ on the EBR1-FT (fluorescently labeled) quadruplex $(0.2 \mu \mathrm{M})$ in $10 \mathrm{mM}$ lithium cacodylate, $\mathrm{pH} 7.2$, containing $10 \mathrm{mM} \mathrm{KCl}+90 \mathrm{mM} \mathrm{LiCl} \mathrm{or} 50 \mathrm{mM} \mathrm{KCl}+50 \mathrm{mM}$ LiCl. (B) CD titration of compound 6 on the EBR1-FT quadruplex $(3 \mu \mathrm{M})$ in $10 \mathrm{mM}$ lithium cacodylate $(\mathrm{pH} 7.2)$ containing $100 \mathrm{mM} \mathrm{KCl}$. (C) $\mathrm{CD}$ titration of compound 7 on the EBR1-FT quadruplex $(3 \mu \mathrm{M})$ in $10 \mathrm{mM}$ lithium cacodylate (pH 7.2$)$ containing $100 \mathrm{mM} \mathrm{KCl}$.

Table 2. Compound Antiparasitic Activity against All Three Parasites and Cytotoxicity Values for MRC5 Control Cell Line of the G4 Ligands 1-7 plus Three Classical G4 Binders and Selectivity Values

\begin{tabular}{|c|c|c|c|c|c|c|c|}
\hline & \multicolumn{4}{|c|}{$\mathrm{IC}_{50}$ parasite $(\mu \mathrm{M})$} & \multicolumn{3}{|c|}{$\mathrm{SI}^{a}$} \\
\hline & L. major & T. brucei & P. falciparum & MRC- $5^{b}$ & L. major & T. brucei & P. falciparum \\
\hline $1 \beta$-glc-NDI & $0.244 \pm 0.007$ & $0.024 \pm 0.001$ & $1.350 \pm 0.636$ & $1.15 \pm 0.29$ & 4.7 & 47.9 & 0.9 \\
\hline $2 \beta$-glcNAc-NDI & $1.041 \pm 0.027$ & $0.089 \pm 0.007$ & $0.360 \pm 0.071$ & $0.51 \pm 0.01$ & 0.5 & 5.7 & 1.4 \\
\hline $3 \beta$-6dglc-NDI & $0.184 \pm 0.009$ & $0.017 \pm 0.007$ & $0.225 \pm 0.120$ & $0.91 \pm 0.32$ & 4.9 & 53.5 & 4.0 \\
\hline $4 \beta$-malt-NDI & $0.921 \pm 0.051$ & $0.099 \pm 0.010$ & $0.370 \pm 0.085$ & $2.04 \pm 0.05$ & 2.2 & 20.6 & 5.5 \\
\hline $5 \alpha$-manC2-NDI & $0.306 \pm 0.019$ & $0.021 \pm 0.003$ & $0.180 \pm 0.099$ & $0.81 \pm 0.44$ & 2.6 & 38.6 & 4.5 \\
\hline $6 \beta$-glcC2-NDI & $0.537 \pm 0.030$ & $0.017 \pm 0.009$ & $0.275 \pm 0.191$ & $0.71 \pm 0.25$ & 1.3 & 41.8 & 2.6 \\
\hline 7 NDI-prop & $0.034 \pm 0.005$ & $0.009 \pm 0.001$ & $0.091 \pm 0.013$ & $0.36 \pm 0.16$ & 10.6 & 40.0 & 4.0 \\
\hline pyridostatin & $5.00 \pm 0.01$ & $7.82 \pm 0.20$ & $2.65 \pm 1.77$ & $5.38 \pm 0.07$ & 1.1 & 0.7 & 2.0 \\
\hline BRACO-19 & $12.73 \pm 0.47$ & $5.51 \pm 0.99$ & $9.70 \pm 4.67$ & $8.33 \pm 2.96$ & 0.7 & 1.5 & 0.9 \\
\hline TMPyP4 & $20.82 \pm 4.86$ & $>10$ & $>25$ & $>25$ & $>1.7$ & & \\
\hline chloroquine & & & $0.0096 \pm 0.003$ & & & & \\
\hline suramin & & $0.038 \pm 0.003$ & & & & & \\
\hline miltefosine & $6.07 \pm 0.37$ & & & & & & \\
\hline
\end{tabular}

glcC2-NDI 6 (Figure 3A and Figure S5). This tendency had been observed previously for the same ligands 6 and 7 when binding to other G4 structures. Yet, $\Delta T_{\mathrm{m}}$ values obtained for EBR1 were lower than those seen with the hTel sequence (at $10 \mathrm{mM} \mathrm{K}^{+}$and $2 \mu \mathrm{M}$ compound, $19{ }^{\circ} \mathrm{C}$ for compound 7 , and $10{ }^{\circ} \mathrm{C}$ for compound 6). $\mathrm{CD}$ titrations with carb-NDIs 6 and 7 on EBR1 also confirmed binding (Figure 3B and Figure 3C). An increase in the $290 \mathrm{~nm}$ band and a decrease in the $265 \mathrm{~nm}$ band were clearly observed upon addition of increasing concentrations of the ligands. These binding results indicate that ligands 6 and 7 not only bind to the T. brucei telomeric sequence but also bind to other G4 structures found within the T. brucei genome.

Antiparasitic Activity and Toxicity of G4 Ligands. The in vitro antiparasitic activities of carb-NDI G4 ligands (1-7) were evaluated against bloodstream forms of T. brucei brucei, against promastigotes of $L$. major, and against $P$. falciparum (Table 2). Cytotoxicity values of these compounds against a human nontumoral lung cell line (MRC-5) were recently reported and are also included in the table. ${ }^{31}$ Selectivity indices (SI) were calculated according to the formula $\mathrm{IC}_{50}(\mathrm{MRC}-5) /$ $\mathrm{IC}_{50}$ (parasite). Pyridostatin, BRACO-19, and TmPyP4 were used as alternative G-quadruplex ligands for comparison. Suramin, miltefosine, and chloroquine were used as positive drug controls for T. brucei, L. major, and P. falciparum, respectively.
Carb-NDI G4 ligands (1-6) presented the best antiparasitic activity against $T$. brucei with $\mathrm{IC}_{50}$ values between 17 and 24 $\mathrm{nM}$ except for compounds $\mathbf{2}$ and $\mathbf{4}$ which were slightly less potent ( 89 and $99 \mathrm{nM}$, respectively). Compounds $\mathbf{1 - 6}$ were more effective against T. brucei than against HT-29, MCF-7, and HeLa cancer cells $\left(\mathrm{IC}_{50}\right.$ values from 0.1 to $2.9 \mu \mathrm{M}$ ), with aglycone-NDI 7 displaying the lowest $\mathrm{IC}_{50}$ of the series in a similar way to the tendency found in cancerous cells. ${ }^{31} \mathrm{IC}_{50}$ values for most of these G-quadruplex ligands are in the same range as that of the commercial drug suramin, used to treat sleeping sickness. At the same time, the selectivity indexes $\left(\mathrm{IC}_{50}(\mathrm{MRC}-5) / \mathrm{IC}_{50}(\right.$ parasite $\left.)\right)$ for compounds $1-7$ were quite high ranging from 38.6 to 53.5 except for compounds $\mathbf{2}$ and $\mathbf{4}$ (5.7 and 20.6, respectively). It is important to note that classical G-quadruplex ligands such as pyridostatin, BRACO-19, and TMPyP4 showed $\mathrm{IC}_{50}$ values in the micromolar range, far higher than those obtained for compounds 1-7. Differences in drug uptake and/or binding to specific G4 targets such as EBR1 may explain these data.

In the cases of L. major and P. falciparum, all $\mathrm{IC}_{50}$ values for Carb-NDI G4 ligands (1-6) and aglycone NDI (7) were higher than those found for T. brucei, although most of them remain in the submicromolar range. This lower effect could be due to differences in drug uptake by the different parasites. Again, aglycone-NDI 7 showed the best antiparasitic activity of the series in both cases, with the carb-NDI presenting slightly 
higher values (5- to 30-fold in L. major and 2- to 15-fold in P. falciparum). The selectivity index of ligands $1-7$ was smaller for these two parasites ranging from 0.5 to 10.6 for L. major and from 0.9 to 5.5 for P. falciparum. We had previously observed differences in antitumor activity depending on how the carbohydrate was attached to the NDI core. ${ }^{31}$ For example, compound $\mathbf{6}$ where the glucose is attached through an ethyl spacer is approximately 10 -fold more active than compound $\mathbf{1}$ where it is directly attached to the core. In the case of their antiparasitic activity, the sugar presentation in the carb-NDI did not show differences except for $P$. falciparum where compound 6 was 5 -fold more active than compound 1. Lastly, the classical G-quadruplex ligands investigated in L. major and P. falciparum (pyridostatin, BRACO-19, and TMPyP4) displayed $\mathrm{IC}_{50}$ values in the micromolar range, being quite less potent than ligands $1-7$.

Next, taking advantage of the intrinsic fluorescence of NDI derivatives $\beta$-glcC2-NDI $6\left(\lambda_{\mathrm{em}}=578 \mathrm{~nm}\right.$, exciting at the maximum absorbance, $\lambda_{\text {exc }}=517 \mathrm{~nm}$, in buffered conditions at $\mathrm{pH} 7.4$, Figure S6) and aglycone-NDI $7\left(\lambda_{\mathrm{em}}=598 \mathrm{~nm}, \lambda_{\text {exc }}=\right.$ $538 \mathrm{~nm}$, Figure S6), we investigated their localization in $T$. brucei by confocal microscopy. After $30 \mathrm{~min}$ of incubation at 37 ${ }^{\circ} \mathrm{C}$, both compounds were detected inside the parasites and aglycone-NDI 7 was mainly found in the nucleus and in the kinetoplast (Figure 4). When longer incubation times (150 min) were used, both compounds localized mainly in the nucleus and in the kinetoplast. We had previously observed a similar uptake trend in HT-29 colon cancer cells and MRC-5 noncancerous cells ${ }^{31}$ where aglycone-NDI 7 entered more rapidly into the cells than carb-NDI derivatives, but at longer times all compounds eventually localized within the nucleus. These results suggest that such G4-ligands could reach and possibly target G-quadruplex structures found in the parasite's genome, such as the telomeric sequence and/or EBR1 sequence.

As G-quadruplex ligands 1-7 have shown nanomolar activity against $T$. brucei and selectivity indexes higher than 40, we decided to perform preliminary toxicity assays in the zebrafish embryo model before future investigation in a mice model of the disease. High fecundity, rapid embryonic development, and high homology to mammalian species make zebrafish a costeffective model for toxicity screening. ${ }^{44}$ Moreover, the embryo is preferred to adult fish because it is predicted that early life stages feel less pain and distress than adult fish. Fast acute toxicity was measured by incubation of zebrafish embryos with increasing concentration of each compound and cumulative mortality/toxicity was observed after $96 \mathrm{hpf}$ (hours postfertilization). ${ }^{45}$ It is important to note that cumulative mortality/ toxicity is due to both developmental impact and organotoxicity. This methodology is becoming more frequently used by medicinal chemists. ${ }^{46}$

Table 3 shows NOEC, LOEC, and $\mathrm{LC}_{50}$ values for acute toxicity on zebrafish embryos and calculated $\mathrm{LD}_{50}$ values on mice for G-quadruplex ligands 1-7. Conversion of $\mathrm{LC}_{50}$ values on zebrafish embryo to $\mathrm{LD}_{50}$ values on mice was carried out by correlation as suggested by Ali et al. ${ }^{47}$ after a large-scale comparison of toxicity in both animal models for 60 watersoluble compounds (Table 3 ). Interestingly, $\beta$-6dglc-NDI (3) and $\beta$-malt-NDI (4), two compounds with low toxicity on MRC-5 cells, were estimated to be the most toxic compounds in mice. On the contrary, glucose or mannose conjugation to the aglycone NDI-prop (such as in compounds 5 and $\mathbf{6}$ ) seems to mitigate the unspecific toxicity associated with these
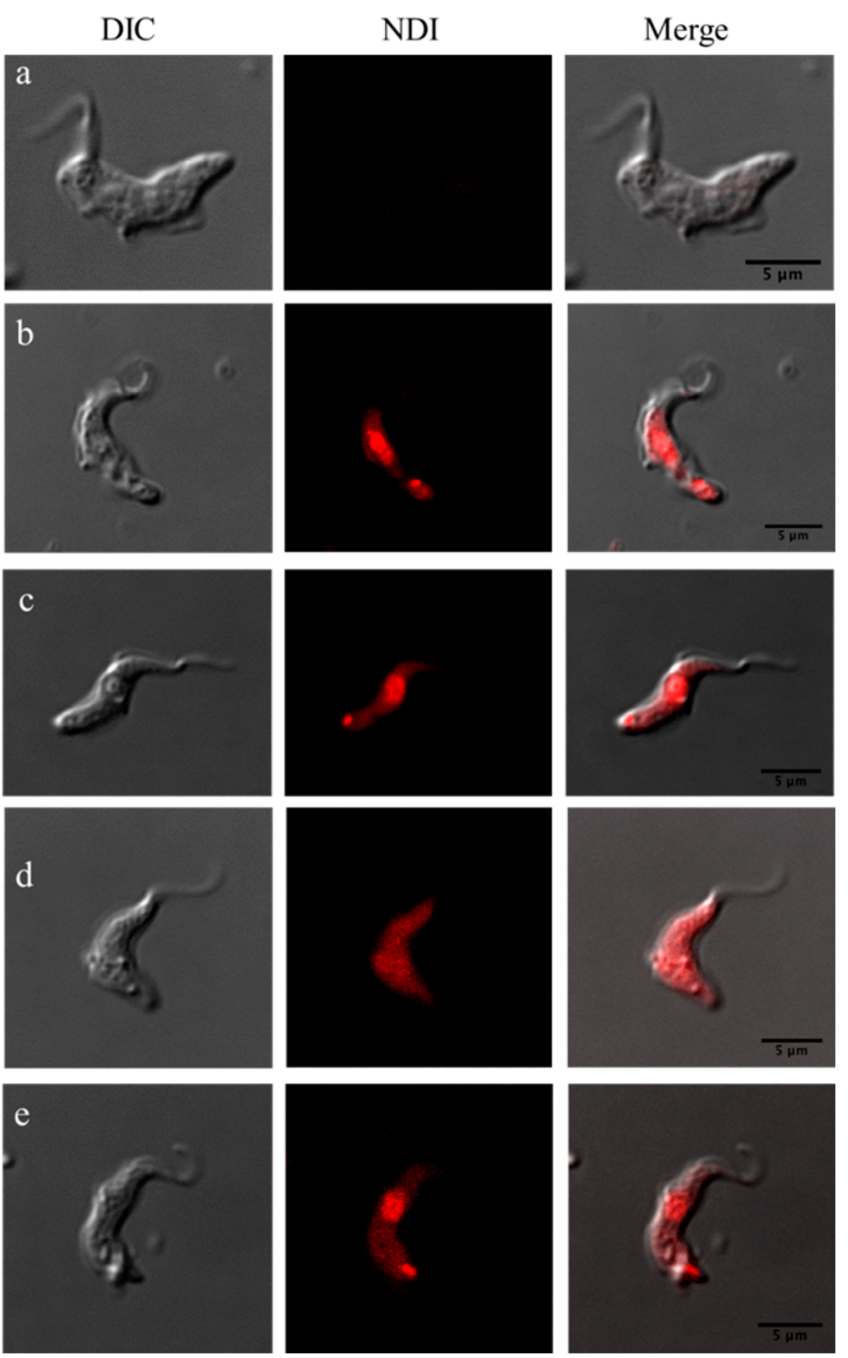

Figure 4. Confocal images of T. brucei parasites after incubation at 5 $\mu \mathrm{M}$ concentration with aglycone-NDI 7 for $30 \mathrm{~min}$ (b) or $150 \mathrm{~min}$ (c) and with $\beta$-glcC2-NDI 6 for $30 \mathrm{~min}$ (d) or $150 \mathrm{~min}$ (e). Control parasites are shown in (a). Scale bar: $5 \mu \mathrm{m}$.

naphthalene diimide ligands. These results point to the relevance that carbohydrate conjugation of G-quadruplex ligands may have on the final toxicity of the compound.

\section{CONCLUSIONS}

Increasing evidence suggests that G4 plays an important role in gene regulation in many organisms. Here, we completed PQS searches on the genome of T. brucei, L. major, and P. falciparum. Several interesting PQS were found, including EBR1 on $T$. brucei, which was also confirmed to form stable G4 structures through biophysical assays. The hTel sequences were also found abundantly in the trypanosomatid parasites in long islands of repetitions.

G-quadruplex ligands such as $\beta$-glcC2-NDI 6 and aglyconeNDI 7, which were previously reported to bind to several G4 structures including hTel, were also capable of binding EBR1 G4, found only in the genome of T. brucei. At the same time, the carb-NDI family and the aglycone NDI prop 7 showed antiparasitic activity against $T$. brucei, L. major, and $P$. falciparum. These G-quadruplex ligands were especially effective against $T$. brucei where they also showed a quite high selectivity versus the human control cell line MRC-5. 
Table 3. NOEC, LOEC, and $\mathrm{LC}_{50}$ Values for Acute Toxicity on Zebrafish Embryos and Calculated $\mathrm{LD}_{50}$ Values on Mice for GQuadruplex Ligands $1-7^{a}$

\begin{tabular}{|c|c|c|c|c|c|}
\hline compd & $\operatorname{NOEC}(\mu \mathrm{M})$ & LOEC $(\mu \mathrm{M})$ & $\mathrm{LC}_{50}(\mathrm{mmol} / \mathrm{L})$ & $\mathrm{LD}_{50}{ }^{b}(\mathrm{mmol} / \mathrm{kg})$ mice & $\mathrm{LD}_{50}{ }^{b}(\mathrm{mg} / \mathrm{kg})$ mice \\
\hline (1) $\beta$-glc-NDI & 100 & NA & $>1$ & $>0.63$ & $>580$ \\
\hline (2) $\beta$-glcNAc-NDI & 100 & NA & $>1$ & $>0.63$ & $>607$ \\
\hline (3) $\beta$-6dglc-NDI & 100 & NA & 0.17 & 0.17 & 154 \\
\hline (4) $\beta$-malt-NDI & 100 & NA & 0.19 & 0.19 & 206 \\
\hline (5) $\beta$-manC2-NDI & 100 & NA & $>1$ & $>0.63$ & $>609$ \\
\hline (6) $\beta$-glcC2-NDI & 100 & NA & $>1$ & $>0.63$ & $>609$ \\
\hline (7) NDI-prop & 100 & 1000 & 0.41 & 0.33 & 178 \\
\hline
\end{tabular}

${ }^{a} \mathrm{LC}_{50}$ (median lethal dose), calculated by fitting sigmoidal curve to mortality data $\left(\mathrm{y}=\mathrm{Bot}+(\right.$ Top $\left.\left.-\mathrm{Bot}) /\left\{1+10^{[k(\mathrm{x} 0}-\log (\mathrm{C})\right)\right]\right\}$. Bot, minimum mortality; Top, maximum mortality; $k$, curve slope; $\mathrm{x} 0, \mathrm{LC}_{50}$ estimated. NOEC: no observed effect concentration, with mortality score of $>20 \%$ assumed as the effect. LOEC: lowest observed effect concentration, with mortality score of $>20 \%$ assumed as the effect. ${ }^{b}$ Extrapolated according to ref 43 .

Confocal microscopy studies localized $\beta$-glcC2-NDI 6 and aglycone-NDI 7 in the nucleus and kinetoplast of T. brucei indicating that G4 structures could be their actual targets. Finally, glucose and mannose conjugation to toxic and potent G4-ligands could be an effective strategy in tuning down unspecific drug toxicity.

\section{EXPERIMENTAL SECTION}

Compound Synthesis and Purity. Compound synthesis was carried out as previously reported. ${ }^{31}$ The purity of all compounds tested was $\geq 95 \%$ and was confirmed by reverse phase HPLC by applying different elution systems and detecting the UV absorption.

Oligonucleotides. All oligonucleotides (Table S1) were purchased from Eurogentec (Belgium) and used without further purification for FRET and CD experiments. NMR samples were purified by centrifugation on $5 \mathrm{kDa}$ filters. Oligonucleotide stock solutions (around $500 \mu \mathrm{M}$ ) were prepared in Milli-Q water and stored at $-20{ }^{\circ} \mathrm{C}$. The exact stock concentrations were determined from the absorbance at $260 \mathrm{~nm}$. For FRET melting and CD experiments, the compounds were solubilized in Milli-Q water at concentrations of either 5 or $10 \mathrm{mM}$, depending on the solubility of the compound.

FRET Melting Assays. The ligand-induced thermal stabilizations $\left(\Delta T_{1 / 2}\right)$ were determined from the difference between the temperature of mid-transition measured without and with the appropriate concentration of ligand, with a final oligonucleotide strand concentration of $0.2 \mu \mathrm{M}$. Three independent experiments were conducted on a Stratagene Mx3005P real-time PCR equipment using duplicate conditions in 96-well plates. The excitation wavelength was set to $492 \mathrm{~nm}$ and the emission recorded at $516 \mathrm{~nm}$. The temperature profile consisted of an initial stabilization at $25^{\circ} \mathrm{C}$ for $5 \mathrm{~min}$ followed by a $1{ }^{\circ} \mathrm{C}$ by minute increase until $95^{\circ} \mathrm{C}$. The induced stabilization was measured in $10 \mathrm{mM}$ lithium cacodylate ( $\mathrm{pH}$ 7.2) supplemented with $10 \mathrm{mM} \mathrm{KCl}$ and $90 \mathrm{mM} \mathrm{LiCl}$.

Circular Dichroism (CD) Spectroscopy. CD spectra were recorded at $25{ }^{\circ} \mathrm{C}$ on a Jasco J-815 equipped with a Peltier temperature controller. Each spectrum corresponds to the average of three scans measured in $1 \mathrm{~cm}$ path length quartz cells at $100 \mathrm{~nm} \mathrm{~min}{ }^{-1}$ (bandwidth of $2 \mathrm{~nm}$, data integration time of $1 \mathrm{~s}$ ). The oligonucleotides were prefolded at $4 \mu \mathrm{M}$ in $10 \mathrm{mM}$ lithium cacodylate ( $\mathrm{pH}$ 7.2) and with the relevant amount of $\mathrm{KCl}$ or $\mathrm{NaCl}$. The ligand concentration was adapted to reach the desired ratio (between 1:0 and $1: 10$ ), in $100 \mathrm{mM} \mathrm{KCl}$.

Cell Culture. MRC5 cells were maintained at $37^{\circ} \mathrm{C}$ and $5 \% \mathrm{CO}_{2}$ in $100 \%$ of humidity in low glucose $(1 \mathrm{~g} / \mathrm{L})$ DMEM supplemented with $10 \%$ heat-inactivated fetal bovine serum (hiFBS), $100 \mathrm{U} / \mathrm{mL}$ penicillin, and $100 \mathrm{mg} / \mathrm{mL}$ streptomycin.

In Vitro Antitrypanosomal Activity. Bloodstream forms (BSF) of T. brucei brucei "single marker" S427 (S16) were grown at $37^{\circ} \mathrm{C}$, $5 \% \mathrm{CO}_{2}$ in HMI-9 medium supplemented with $10 \%$ hiFBS. Drug susceptibility assay was performed as described in Carvalho et al. ${ }^{48}$ Briefly, parasites $\left(1 \times 10^{4}\right.$ BSF per $\left.\mathrm{mL}\right)$ were incubated in 96-well plates with increasing concentration of drugs/compounds for $72 \mathrm{~h}$ at $37{ }^{\circ} \mathrm{C}, 5 \% \mathrm{CO}_{2}$ in culture medium. Cell proliferation was determined using the alamarBlue assay ${ }^{49}$ in vitro. Fluorescence was recorded with an Infinite F200 microplate reader (Tecan Austria GmbH, Austria) equipped with 550 and $590 \mathrm{~nm}$ filters for excitation and emission wavelengths, respectively.

In Vitro Antileishmanial Activity. The experiments of drug susceptibility on L. major (MHOM/IL/80/Friedlin) were carried out as described previously. ${ }^{50}$ Briefly, $1 \times 10^{6}$ promastigotes per $\mathrm{mL}$ were incubated for $72 \mathrm{~h}$ at $28{ }^{\circ} \mathrm{C}$ in 96-well plates in modified RPMI-1640 medium (Invitrogen, Carlsbad, CA) plus 10\% hiFBS, containing increasing concentration of drugs. Cell proliferation was determined using a MTT-based assay. ${ }^{51}$ The absorbance was measured at a wavelength of $540 \mathrm{~nm}$.

In Vitro Antimalarial Activity. Drug effects on in vitro $P$. falciparum growth were measured in microtiter plates according to Desjardins et al. $^{52}$ The final volume in each well was $200 \mu \mathrm{L}$, consisting of $50 \mu \mathrm{L}$ of complete medium (RPMI $1640+10 \% \mathrm{AB}$ human serum) without (controls) or with drug and $150 \mu \mathrm{L}$ of $P$. falciparum infected erythrocyte (3D7 strain) suspension (1.5\% final hematocrit and $0.6 \%$ parasitemia). The drugs dissolved in DMSO were diluted in complete medium so that the final DMSO concentration never exceeded $0.25 \%$. After $48 \mathrm{~h}$ incubation at $37{ }^{\circ} \mathrm{C}, 30 \mu \mathrm{L}$ of complete medium containing $0.6 \mu \mathrm{Ci}[3 \mathrm{H}]$-hypoxanthine were added to each well. After $18 \mathrm{~h}$ at $37^{\circ} \mathrm{C}$, cells were lyzed using an automatic cell harvester, and the parasite macromolecules, including radioactive nucleic acids, were retained onto glass fiber filters. The filters were counted for radioactivity, after adding scintillation cocktail, in a liquid scintillation spectrometer. Radioactivity background was obtained from incubation of noninfected erythrocytes under the same condition and deduced. Parasitic viability was expressed as $\mathrm{IC}_{50}$ which is the drug concentration leading to $50 \%$ parasite growth inhibition.

Cytotoxicity Assay. MRC5 cells were harvested by trypsinization $(0.25 \%)$ and seeded in 96-well plates (5000 cells in $100 \mu \mathrm{L} /$ well) in the presence of increasing concentrations of NDI-compounds. Cellular toxicity was determined using the colorimetric MTT-based assay after incubation at $37{ }^{\circ} \mathrm{C}$ for or $72 \mathrm{~h} .{ }^{51}$ The results are expressed as the concentration of compound that reduces cell growth by $50 \%$ versus untreated control cells $\left(\mathrm{IC}_{50}\right)$.

Zebrafish Toxicity. Acute toxicity assay was carried out by Zeclinics (Barcelona, Spain). Lyophilized compounds were dissolved in $100 \%$ DMSO. DMSO volume was calculated for a $100 \mathrm{mM}$ stock solution. To proceed to zebrafish embryo drug incubation, compounds were diluted in $1 \mathrm{~mL}$ of $0.1 \% \mathrm{DMSO} / \mathrm{E} 3$ medium to obtain 5 logarithmic concentrations: $0.01 \mu \mathrm{M}, 0.1 \mu \mathrm{M}, 1 \mu \mathrm{M}, 10 \mu \mathrm{M}$, and 100 $\mu \mathrm{M}$ (for drugs 1, 2, 3, 4, 5, 6, 7) and $0.1 \mu \mathrm{M}, 1 \mu \mathrm{M}, 10 \mu \mathrm{M}, 100 \mu \mathrm{M}$, and $1 \mathrm{mM}$ (for drugs 8, 9, 10).

Zebrafish Embryos Preparation. Fertilized embryos of zebrafish (Danio rerio), strain $\mathrm{AB}$, were collected in E3 medium in Petri dishes. At $3 \mathrm{~h}$ postfertilization (hpf), after abnormal or not fertilized embryos were discarded, 20 healthy embryos per condition were placed in wells of a 24-well plate. Once embryos were placed in each well, E3 medium 
was replaced by the different dilutions prepared previously for every compound and concentration.

Acute Toxicity Assay. Embryos were grown from $3 \mathrm{hpf}$ to $96 \mathrm{hpf}$ at $28.5^{\circ} \mathrm{C}$. At $96 \mathrm{~h}^{53}$ after treatment mortality $\mathrm{LC}_{50}$ will be determined: $\mathrm{LC}_{50}$ (median lethal dose), calculated by fitting sigmoidal curve to mortality data $\left(y=\right.$ Bot $+($ Top - Bot $) /\left(1+10^{[k(x 0-\log (C))]}\right)$. Bot, minimum mortality; Top, maximum mortality; $k$, curve slope; $\mathrm{x} 0, \mathrm{LC}_{50}$ estimated.

Negative control: ${ }^{54} 0.1 \%$ DMSO, in three replicates. Positive controls: 4-diethylaminobenzaldehyde (DEAB) at five different concentrations $(0.1 \mu \mathrm{M}, 1 \mu \mathrm{M}, 10 \mu \mathrm{M}, 100 \mu \mathrm{M}, 1 \mathrm{mM})$. DEAB is a competitive inhibitor of aldehyde dehydrogenases known to generate toxic and teratogenic effects.

Absorption and Fluorescence Spectra. Absorption and emission spectra were recorded in $(1.0-1.5) \times 10^{-5} \mathrm{M}$ aqueous solutions (buffered at $\mathrm{pH} 7.4,1 \times 10^{-3} \mathrm{M}$ Tris- $\mathrm{HCl}$ ) on a JASCO V$550 \mathrm{UV} /$ vis spectrophotometer and on a PerkinElmer LS-65 fluorometer, respectively. The molar absorptivity has been calculated applying the Beer-Lambert relationship to three independent measurements. Fluorescence spectra were measured using $1 \mathrm{~nm}$ steps and $0.5-1 \mathrm{~s}$ dwell time. Right angle detection was used. All the measurements were carried out at $22{ }^{\circ} \mathrm{C}$ in quartz cuvettes with path length of $1 \mathrm{~cm}$. The fluorescence spectra were measured in airequilibrated solutions absorbing less than 0.1 at all wavelengths to avoid inner filter effects and reabsorption of emission.

Confocal Microscopy. T. brucei parasites were incubated with 5 $\mu \mathrm{M}$ NDI compounds in $0.5 \mathrm{~mL}$ of each respective medium for 30 and $150 \mathrm{~min}$ at $37^{\circ} \mathrm{C}$ and $100 \%$ of humidity. Then the parasites were fixed with paraformaldeide $4 \%$ for $30 \mathrm{~min}$, washed twice in cold phosphate buffered saline (PBS), and processed by microscope observation. Images were acquired using a Leica SP5 confocal microscope (exciting at $488 \mathrm{~nm}$ and detecting the emission between 540 and $650 \mathrm{~nm}$ ), while the images were deconvoluted using Huygens Professional image processing software from Scientific Volume Imaging (http://www.svi. $\mathrm{nl}$ ). The merge of the images were made with Fiji software (https:// fiji.sc/).

\section{ASSOCIATED CONTENT}

\section{S Supporting Information}

The Supporting Information is available free of charge on the ACS Publications website at DOI: 10.1021/acs.jmedchem.7b01672.

DNA sequences used in the present study; PQS density found per chromosome of each parasite examined; CD spectra of EBR1 in the absence and presence of different concentrations of $\mathrm{Na}^{+}$; $\mathrm{CD}$ experiments with EBR1mut sequence; imino region of NMR spectra for EBR1 at different temperatures; characterization of EBR1-FT sequence; FRET-melting stabilization induced by compounds 6 and 7 on EBR1-FT G-quadruplex; absorption and emission spectra of 6 and 7 in water; zebrafish embryo graphs of concentration-mortality response (PDF)

Molecular formula strings and associated biological data (CSV)

\section{AUTHOR INFORMATION}

\section{Corresponding Authors}

*J.M.P.-V.: phone, +34-958181685; e-mail, josepv@ipb.csic.es. *J.C.M.: phone, +34-958181644; e-mail, jcmorales@ipb.csic.es. ORCID $\odot$

Mauro Freccero: 0000-0002-7438-1526

Jean-Louis Mergny: 0000-0003-3043-8401

Juan Carlos Morales: 0000-0003-2400-405X

\section{Notes}

The authors declare no competing financial interest.

\section{ACKNOWLEDGMENTS}

This work was supported by the Spanish Ministerio de Economía y Competitividad (Grants CTQ2012-35360, CTQ2015-64275-P, and SAF2016-80228-R), Junta de Andalucía (Grant BIO1786), Worldwide Cancer Research Foundation (Grant 16-0290), Italian Association for Cancer Research (AIRC, Grant IG2013-14708), Agence Nationale de la Recherche (ANR Quarpdiem, Grant ANR-12-BSV8-0008-01), the SYMBIT project (Reg. No. CZ.02.1.01/0.0/0.0/15_003/ 0000477) financed by the ERDF, and FEDER funds from the EU are gratefully acknowledged. M.A.-R. and M.M.-G. thank Ministerio de Educación, Cultura y Deporte for a FPU and a FPI predoctoral fellowship, respectively. E.B.-R. is a student of the pharmacy Ph.D. program of the University of Granada (Spain).

\section{ABBREVIATIONS USED}

PQS, putative G-quadruplex forming sequence; carb-NDI, carbohydrate conjugated naphthalene diimide; hTel, human telomerase DNA sequence; VSG, variable surface glycoprotein; ORF, open reading frames; GLUT, glucose transporter; CD, circular dichroism; TDS, thermal difference spectroscopy; IDS, isothermal difference spectroscopy; FRET, Förster resonance energy transfer; SI, selectivity index; NDI, naphthalene diimide

\section{REFERENCES}

(1) (a) Huppert, J. L.; Bugaut, A.; Kumari, S.; Balasubramanian, S. Gquadruplexes: the beginning and end of UTRs. Nucleic Acids Res. 2008, 36 (19), 6260-6268. (b) Huppert, J. L. Four-stranded nucleic acids: structure, function and targeting of G-quadruplexes. Chem. Soc. Rev. 2008, 37 (7), 1375-1384. (c) Balasubramanian, S.; Neidle, S. Gquadruplex nucleic acids as therapeutic targets. Curr. Opin. Chem. Biol. 2009, 13 (3), 345-353. (d) Neidle, S. The structures of quadruplex nucleic acids and their drug complexes. Curr. Opin. Struct. Biol. 2009, 19 (3), 239-250. (e) Bedrat, A.; Lacroix, L.; Mergny, J. L. Reevaluation of G-quadruplex propensity with G4Hunter. Nucleic Acids Res. 2016, 44 (4), 1746-1759.

(2) (a) Chambers, V. S.; Marsico, G.; Boutell, J. M.; Di Antonio, M.; Smith, G. P.; Balasubramanian, S. High-throughput sequencing of DNA G-quadruplex structures in the human genome. Nat. Biotechnol. 2015, 33 (8), 877-881. (b) Huppert, J. L.; Balasubramanian, S. Prevalence of quadruplexes in the human genome. Nucleic Acids Res. 2005, 33 (9), 2908-2916. (c) Kwok, C. K.; Merrick, C. J. GQuadruplexes: prediction, characterization, and biological application. Trends Biotechnol. 2017, 35 (10), 997-1013.

(3) Rodriguez, R.; Miller, K. M.; Forment, J. V.; Bradshaw, C. R.; Nikan, M.; Britton, S.; Oelschlaegel, T.; Xhemalce, B.; Balasubramanian, S.; Jackson, S. P. Small-molecule-induced DNA damage identifies alternative DNA structures in human genes. Nat. Chem. Biol. 2012, 8 (3), 301-310.

(4) (a) Kruisselbrink, E.; Guryev, V.; Brouwer, K.; Pontier, D. B.; Cuppen, E.; Tijsterman, M. Mutagenic capacity of endogenous G4 DNA underlies genome instability in FANCJ-defective C. elegans. Curr. Biol. 2008, 18 (12), 900-905. (b) Koole, W.; van Schendel, R.; Karambelas, A. E.; van Heteren, J. T.; Okihara, K. L.; Tijsterman, M. A Polymerase Theta-dependent repair pathway suppresses extensive genomic instability at endogenous G4 DNA sites. Nat. Commun. 2014, 5, 3216. (c) Castillo Bosch, P.; Segura-Bayona, S.; Koole, W.; van Heteren, J. T.; Dewar, J. M.; Tijsterman, M.; Knipscheer, P. FANCJ promotes DNA synthesis through G-quadruplex structures. EMBO J. 2014, 33 (21), 2521-2533. (d) Ohnmacht, S. A.; Neidle, S. Smallmolecule quadruplex-targeted drug discovery. Bioorg. Med. Chem. Lett. 2014, 24 (12), 2602-2612. (e) Mendoza, O.; Bourdoncle, A.; Boule, J. 
B.; Brosh, R. M., Jr.; Mergny, J. L. G-quadruplexes and helicases. Nucleic Acids Res. 2016, 44 (5), 1989-2006.

(5) Sarkies, P.; Reams, C.; Simpson, L. J.; Sale, J. E. Epigenetic instability due to defective replication of structured DNA. Mol. Cell 2010, 40 (5), 703-713.

(6) Verma, A.; Halder, K.; Halder, R.; Yadav, V. K.; Rawal, P.; Thakur, R. K.; Mohd, F.; Sharma, A.; Chowdhury, S. Genome-wide computational and expression analyses reveal G-quadruplex DNA motifs as conserved cis-regulatory elements in human and related species. J. Med. Chem. 2008, 51 (18), 5641-5649.

(7) (a) Hershman, S. G.; Chen, Q.; Lee, J. Y.; Kozak, M. L.; Yue, P.; Wang, L. S.; Johnson, F. B. Genomic distribution and functional analyses of potential G-quadruplex-forming sequences in Saccharomyces cerevisiae. Nucleic Acids Res. 2008, 36 (1), 144-156. (b) Johnson, J. E.; Smith, J. S.; Kozak, M. L.; Johnson, F. B. In vivo veritas: Using yeast to probe the biological functions of Gquadruplexes. Biochimie 2008, 90 (8), 1250-1263.

(8) (a) Rawal, P.; Kummarasetti, V. B.; Ravindran, J.; Kumar, N.; Halder, K.; Sharma, R.; Mukerji, M.; Das, S. K.; Chowdhury, S. Genome-wide prediction of G4 DNA as regulatory motifs: role in Escherichia coli global regulation. Genome Res. 2006, 16 (5), 644-655. (b) Wieland, M.; Hartig, J. S. Investigation of mRNA quadruplex formation in Escherichia coli. Nat. Protoc. 2009, 4 (11), 1632-1640.

(9) (a) Perrone, R.; Nadai, M.; Frasson, I.; Poe, J. A.; Butovskaya, E.; Smithgall, T. E.; Palumbo, M.; Palu, G.; Richter, S. N. A dynamic Gquadruplex region regulates the HIV-1 long terminal repeat promoter. J. Med. Chem. 2013, 56 (16), 6521-6530. (b) Rajendran, A.; Endo, M.; Hidaka, K.; Tran, P. L.; Mergny, J. L.; Gorelick, R. J.; Sugiyama, H. HIV-1 nucleocapsid proteins as molecular chaperones for tetramolecular antiparallel G-quadruplex formation. J. Am. Chem. Soc. 2013, 135 (49), 18575-18585. (c) Amrane, S.; Kerkour, A.; Bedrat, A.; Vialet, B.; Andreola, M. L.; Mergny, J. L. Topology of a DNA Gquadruplex structure formed in the HIV-1 promoter: a potential target for anti-HIV drug development. J. Am. Chem. Soc. 2014, 136 (14), 5249-5252. (d) Artusi, S.; Nadai, M.; Perrone, R.; Biasolo, M. A.; Palu, G.; Flamand, L.; Calistri, A.; Richter, S. N. The Herpes Simplex Virus-1 genome contains multiple clusters of repeated G-quadruplex: implications for the antiviral activity of a G-quadruplex ligand. Antiviral Res. 2015, 118, 123-131.

(10) Harris, L. M.; Merrick, C. J. G-quadruplexes in pathogens: a common route to virulence control? PLoS Pathog. 2015, 11 (2), e1004562.

(11) Gardner, M. J.; Hall, N.; Fung, E.; White, O.; Berriman, M.; Hyman, R. W.; Carlton, J. M.; Pain, A.; Nelson, K. E.; Bowman, S.; Paulsen, I. T.; James, K.; Eisen, J. A.; Rutherford, K.; Salzberg, S. L.; Craig, A.; Kyes, S.; Chan, M. S.; Nene, V.; Shallom, S. J.; Suh, B.; Peterson, J.; Angiuoli, S.; Pertea, M.; Allen, J.; Selengut, J.; Haft, D.; Mather, M. W.; Vaidya, A. B.; Martin, D. M.; Fairlamb, A. H.; Fraunholz, M. J.; Roos, D. S.; Ralph, S. A.; McFadden, G. I.; Cummings, L. M.; Subramanian, G. M.; Mungall, C.; Venter, J. C.; Carucci, D. J.; Hoffman, S. L.; Newbold, C.; Davis, R. W.; Fraser, C. M.; Barrell, B. Genome sequence of the human malaria parasite Plasmodium falciparum. Nature 2002, 419 (6906), 498-511.

(12) (a) Stanton, A.; Harris, L. M.; Graham, G.; Merrick, C. J. Recombination events among virulence genes in malaria parasites are associated with G-quadruplex-forming DNA motifs. BMC Genomics 2016, 17 (1), 859. (b) Smargiasso, N.; Gabelica, V.; Damblon, C.; Rosu, F.; De Pauw, E.; Teulade-Fichou, M. P.; Rowe, J. A.; Claessens, A. Putative DNA G-quadruplex formation within the promoters of Plasmodium falciparum var genes. BMC Genomics 2009, 10, 362.

(13) Bottius, E.; Bakhsis, N.; Scherf, A. Plasmodium falciparum telomerase: de novo telomere addition to telomeric and nontelomeric sequences and role in chromosome healing. Mol. Cell. Biol. 1998, 18 (2), 919-925.

(14) Dore, E.; Pace, T.; Ponzi, M.; Scotti, R.; Frontali, C. Homologous telomeric sequences are present in different species of the genus Plasmodium. Mol. Biochem. Parasitol. 1986, 21 (2), 121127.
(15) (a) Duraisingh, M. T.; Voss, T. S.; Marty, A. J.; Duffy, M. F.; Good, R. T.; Thompson, J. K.; Freitas-Junior, L. H.; Scherf, A.; Crabb, B. S.; Cowman, A. F. Heterochromatin silencing and locus repositioning linked to regulation of virulence genes in Plasmodium falciparum. Cell 2005, 121 (1), 13-24. (b) Freitas-Junior, L. H.; Hernandez-Rivas, R.; Ralph, S. A.; Montiel-Condado, D.; RuvalcabaSalazar, O. K.; Rojas-Meza, A. P.; Mancio-Silva, L.; Leal-Silvestre, R. J.; Gontijo, A. M.; Shorte, S.; Scherf, A. Telomeric heterochromatin propagation and histone acetylation control mutually exclusive expression of antigenic variation genes in malaria parasites. Cell 2005, 121 (1), 25-36.

(16) Claessens, A.; Hamilton, W. L.; Kekre, M.; Otto, T. D.; Faizullabhoy, A.; Rayner, J. C.; Kwiatkowski, D. Generation of antigenic diversity in Plasmodium falciparum by structured rearrangement of Var genes during mitosis. PLoS Genet. 2014, 10 (12), e1004812.

(17) Scherf, A.; Hernandez-Rivas, R.; Buffet, P.; Bottius, E.; Benatar, C.; Pouvelle, B.; Gysin, J.; Lanzer, M. Antigenic variation in malaria: in situ switching, relaxed and mutually exclusive transcription of var genes during intra-erythrocytic development in Plasmodium falciparum. EMBO J. 1998, 17 (18), 5418-5426.

(18) (a) Blackburn, E. H.; Challoner, P. B. Identification of a telomeric DNA sequence in Trypanosoma brucei. Cell 1984, 36 (2), 447-457. (b) Van der Ploeg, L. H.; Liu, A. Y.; Borst, P. Structure of the growing telomeres of Trypanosomes. Cell 1984, 36 (2), 459-468.

(19) (a) Lanzer, M.; Fischer, K.; Le Blancq, S. M. Parasitism and chromosome dynamics in protozoan parasites: is there a connection? Mol. Biochem. Parasitol. 1995, 70 (1-2), 1-8. (b) Crozatier, M.; Van der Ploeg, L. H.; Johnson, P. J.; Gommers-Ampt, J.; Borst, P. Structure of a telomeric expression site for variant specific surface antigens in Trypanosoma brucei. Mol. Biochem. Parasitol. 1990, 42 (1), 1-12.

(20) Glover, L.; Alsford, S.; Horn, D. DNA break site at fragile subtelomeres determines probability and mechanism of antigenic variation in African trypanosomes. PLoS Pathog. 2013, 9 (3), e1003260.

(21) (a) Borst, P.; Greaves, D. R. Programmed gene rearrangements altering gene expression. Science 1987, 235 (4789), 658-67. (b) Devlin, R.; Marques, C. A.; McCulloch, R. Does DNA replication direct locus-specific recombination during host immune evasion by antigenic variation in the African trypanosome? Curr. Genet. 2017, 63 (3), 441-449.

(22) Benne, R.; Van den Burg, J.; Brakenhoff, J. P.; Sloof, P.; Van Boom, J. H.; Tromp, M. C. Major transcript of the frameshifted coxII gene from trypanosome mitochondria contains four nucleotides that are not encoded in the DNA. Cell 1986, 46 (6), 819-826.

(23) Leeder, W. M.; Hummel, N. F.; Goringer, H. U. Multiple Gquartet structures in pre-edited mRNAs suggest evolutionary driving force for RNA editing in trypanosomes. Sci. Rep. 2016, 6, 29810.

(24) Cullen, D. R.; Mocerino, M. A Brief review of drug discovery research for human african Trypanosomiasis. Curr. Med. Chem. 2017, 24 (7), 701-717.

(25) Balasubramanian, S.; Hurley, L. H.; Neidle, S. Targeting Gquadruplexes in gene promoters: a novel anticancer strategy? Nat. Rev. Drug Discovery 2011, 10 (4), 261-275.

(26) (a) Davis, J. T. G-quartets 40 years later: from 5'-GMP to molecular biology and supramolecular chemistry. Angew. Chem., Int. Ed. 2004, 43 (6), 668-698. (b) Maji, B.; Bhattacharya, S. Advances in the molecular design of potential anticancer agents via targeting of human telomeric DNA. Chem. Commun. 2014, 50 (49), 6422-6438. (c) Xiong, Y.-X.; Huang, Z.-S.; Tan, J.-H. Targeting G-quadruplex nucleic acids with heterocyclic alkaloids and their derivatives. Eur. J. Med. Chem. 2015, 97, 538-551.

(27) (a) Métifiot, M.; Amrane, S.; Mergny, J.-L.; Andreola, M.-L. Anticancer molecule AS1411 exhibits low nanomolar antiviral activity against HIV-1. Biochimie 2015, 118, 173-175. (b) Perrone, R.; Doria, F.; Butovskaya, E.; Frasson, I.; Botti, S.; Scalabrin, M.; Lago, S.; Grande, V.; Nadai, M.; Freccero, M.; Richter, S. N. Synthesis, binding and antiviral properties of potent core-extended naphthalene diimides targeting the HIV-1 long terminal repeat promoter G-quadruplexes. J. 
Med. Chem. 2015, 58 (24), 9639-9652. (c) Biswas, B.; Kandpal, M.; Vivekanandan, P. A G-quadruplex motif in an envelope gene promoter regulates transcription and virion secretion in HBV genotype $\mathrm{B}$. Nucleic Acids Res. 2017, 45 (19), 11268-11280.

(28) De Cian, A.; Grellier, P.; Mouray, E.; Depoix, D.; Bertrand, H.; Monchaud, D.; Teulade-Fichou, M. P.; Mergny, J. L.; Alberti, P. Plasmodium telomeric sequences: structure, stability and quadruplex targeting by small compounds. ChemBioChem 2008, 9 (16), 27302739.

(29) Guillon, J.; Cohen, A.; Gueddouda, N. M.; Das, R. N.; Moreau, S.; Ronga, L.; Savrimoutou, S.; Basmaciyan, L.; Monnier, A.; Monget, M.; Rubio, S.; Garnerin, T.; Azas, N.; Mergny, J. L.; Mullie, C.; Sonnet, P. Design, synthesis and antimalarial activity of novel bis $\{\mathrm{N}$ [(pyrrolo[1,2-a]quinoxalin-4-yl)benzyl]-3-aminopropyl\}amine derivatives. J. Enzyme Inhib. Med. Chem. 2017, 32 (1), 547-563.

(30) Calvo, E. P.; Wasserman, M. G-Quadruplex ligands: Potent inhibitors of telomerase activity and cell proliferation in Plasmodium falciparum. Mol. Biochem. Parasitol. 2016, 207 (1), 33-38.

(31) Arevalo-Ruiz, M.; Doria, F.; Belmonte-Reche, E.; De Rache, A.; Campos-Salinas, J.; Lucas, R.; Falomir, E.; Carda, M.; Perez-Victoria, J. M.; Mergny, J. L.; Freccero, M.; Morales, J. C. Synthesis, binding properties, and differences in cell uptake of G-quadruplex ligands based on carbohydrate naphthalene diimide conjugates. Chem. - Eur. J. 2017, 23 (9), 2157-2164.

(32) (a) Calvaresi, E. C.; Hergenrother, P. J. Glucose conjugation for the specific targeting and treatment of cancer. Chem. Sci. 2013, 4 (6), 2319-2333. (b) Pohl, J.; Bertram, B.; Hilgard, P.; Nowrousian, M. R.; Stuben, J.; Wiessler, M. D-19575- a sugar-linked isophosphoramide mustard derivative exploiting transmembrane glucose transport. Cancer Chemother. Pharmacol. 1995, 35 (5), 364-370. (c) Liu, P.; Lu, Y.; Gao, X.; Liu, R.; Zhang-Negrerie, D.; Shi, Y.; Wang, Y.; Wang, S.; Gao, Q. Highly water-soluble platinum(II) complexes as GLUT substrates for targeted therapy: improved anticancer efficacy and transportermediated cytotoxic properties. Chem. Commun. 2013, 49 (24), 2421-2423.

(33) Burchmore, R. J.; Landfear, S. M. Differential regulation of multiple glucose transporter genes in Leishmania mexicana. J. Biol. Chem. 1998, 273 (44), 29118-29126.

(34) Rodriguez-Contreras, D.; Feng, X.; Keeney, K. M.; Bouwer, H. G. A.; Landfear, S. M. Phenotypic characterization of a glucose transporter null mutant in Leishmania mexicana. Mol. Biochem. Parasitol. 2007, 153 (1), 9-18.

(35) (a) Feng, X.; Rodriguez-Contreras, D.; Buffalo, C.; Bouwer, H. G. A.; Kruvand, E.; Beverley, S. M.; Landfear, S. M. Amplification of an alternate transporter gene suppresses the avirulent phenotype of glucose transporter null mutants in Leishmania mexicana. Mol. Microbiol. 2009, 71 (2), 369-381. (b) Rodríguez-Contreras, D.; Landfear, S. M. Metabolic Changes in Glucose Transporter-deficient Leishmania mexicana and Parasite Virulence. J. Biol. Chem. 2006, 281, 20068-20076.

(36) Woodrow, C. J.; Penny, J. I.; Krishna, S. Intraerythrocytic Plasmodium falciparum expresses a high affinity facilitative hexose transporter. J. Biol. Chem. 1999, 274 (11), 7272-7277.

(37) Barrett, M. P.; Tetaud, E.; Seyfang, A.; Bringaud, F.; Baltz, T. Trypanosome glucose transporters. Mol. Biochem. Parasitol. 1998, 91 (1), 195-205.

(38) Kikin, O.; D’Antonio, L.; Bagga, P. S. QGRS Mapper: a webbased server for predicting G-quadruplexes in nucleotide sequences. Nucleic Acids Res. 2006, 34 (Web Server), W676-W682.

(39) Karsisiotis, A. I.; Hessari, N. M.; Novellino, E.; Spada, G. P.; Randazzo, A.; Webba da Silva, M. Topological characterization of nucleic acid G-quadruplexes by UV absorption and circular dichroism. Angew. Chem., Int. Ed. 2011, 50 (45), 10645-8.

(40) (a) Diveshkumar, K. V.; Sakrikar, S.; Harikrishna, S.; Dhamodharan, V.; Pradeepkumar, P. I. Targeting promoter Gquadruplex DNAs by indenopyrimidine-based ligands. ChemMedChem 2014, 9 (12), 2754-2765. (b) Perrone, R.; Nadai, M.; Poe, J. A.; Frasson, I.; Palumbo, M.; Palu, G.; Smithgall, T. E.; Richter, S. N. Formation of a unique cluster of G-quadruplex structures in the HIV-1
Nef coding region: implications for antiviral activity. PLoS One 2013, 8 (8), e73121.

(41) Mergny, J. L.; Li, J.; Lacroix, L.; Amrane, S.; Chaires, J. B. Thermal difference spectra: a specific signature for nucleic acid structures. Nucleic Acids Res. 2005, 33 (16), e138.

(42) Mergny, J. L.; Phan, A. T.; Lacroix, L. Following G-quartet formation by UV-spectroscopy. FEBS Lett. 1998, 435 (1), 74-78.

(43) Feigon, J.; Koshlap, K. M.; Smith, F. W. ${ }^{1}$ H NMR spectroscopy of DNA triplexes and quadruplexes. Methods Enzymol. 1995, 261, $225-255$.

(44) Sipes, N. S.; Padilla, S.; Knudsen, T. B. Zebrafish: as an integrative model for twenty-first century toxicity testing. Birth Defects Res., Part C 2011, 93 (3), 256-267.

(45) Busquet, F.; Strecker, R.; Rawlings, J. M.; Belanger, S. E.; Braunbeck, T.; Carr, G. J.; Cenijn, P.; Fochtman, P.; Gourmelon, A.; Hubler, N.; Kleensang, A.; Knobel, M.; Kussatz, C.; Legler, J.; Lillicrap, A.; Martinez-Jeronimo, F.; Polleichtner, C.; Rzodeczko, H.; Salinas, E.; Schneider, K. E.; Scholz, S.; van den Brandhof, E. J.; van der Ven, L. T.; Walter-Rohde, S.; Weigt, S.; Witters, H.; Halder, M. OECD validation study to assess intra- and inter-laboratory reproducibility of the zebrafish embryo toxicity test for acute aquatic toxicity testing. Regul. Toxicol. Pharmacol. 2014, 69 (3), 496-511.

(46) (a) Ledoux, A.; St-Gelais, A.; Cieckiewicz, E.; Jansen, O.; Bordignon, A.; Illien, B.; Di Giovanni, N.; Marvilliers, A.; Hoareau, F.; Pendeville, H.; Quetin-Leclercq, J.; Frederich, M. Antimalarial activities of alkyl cyclohexenone derivatives isolated from the leaves of Poupartia borbonica. J. Nat. Prod. 2017, 80 (6), 1750-1757. (b) Teijeiro-Valino, C.; Yebra-Pimentel, E.; Guerra-Varela, J.; Csaba, N.; Alonso, M. J.; Sanchez, L. Assessment of the permeability and toxicity of polymeric nanocapsules using the zebrafish model. Nanomedicine 2017, 12 (17), 2069-2082.

(47) Ali, S.; van Mil, H. G. J.; Richardson, M. K. Large-scale assessment of the zebrafish embryo as a possible predictive model in toxicity testing. PLoS One 2011, 6 (6), e21076.

(48) Carvalho, L.; Martinez-Garcia, M.; Perez-Victoria, I.; Manzano, J. I.; Yardley, V.; Gamarro, F.; Perez-Victoria, J. M. The oral antimalarial drug tafenoquine shows activity against Trypanosoma brucei. Antimicrob. Agents Chemother. 2015, 59 (10), 6151-6160.

(49) Raz, B.; Iten, M.; Grether-Buhler, Y.; Kaminsky, R.; Brun, R. The Alamar Blue assay to determine drug sensitivity of African trypanosomes (T.b. rhodesiense and T.b. gambiense) in vitro. Acta Trop. 1997, 68 (2), 139-147.

(50) Perez-Victoria, J. M.; Bavchvarov, B. I.; Torrecillas, I. R; Martinez-Garcia, M.; Lopez-Martin, C.; Campillo, M.; Castanys, S.; Gamarro, F. Sitamaquine overcomes ABC-mediated resistance to miltefosine and antimony in Leishmania. Antimicrob. Agents Chemother. 2011, 55 (8), 3838-3844.

(51) Mosmann, T. Rapid colorimetric assay for cellular growth and survival: application to proliferation and cytotoxicity assays. J. Immunol. Methods 1983, 65 (1-2), 55-63.

(52) Desjardins, R. E.; Canfield, C. J.; Haynes, J. D.; Chulay, J. D. Quantitative assessment of antimalarial activity in vitro by a semiautomated microdilution technique. Antimicrob. Agents Chemother. 1979, 16 (6), 710-718.

(53) At $24 \mathrm{~h}$ coagulated eggs were removed from the well to avoid contamination of E3 medium due to tissue decomposition.

(54) If negative control cumulative mortality is greater than $20 \%$, the experiment was not considered significant and had to be repeated. 